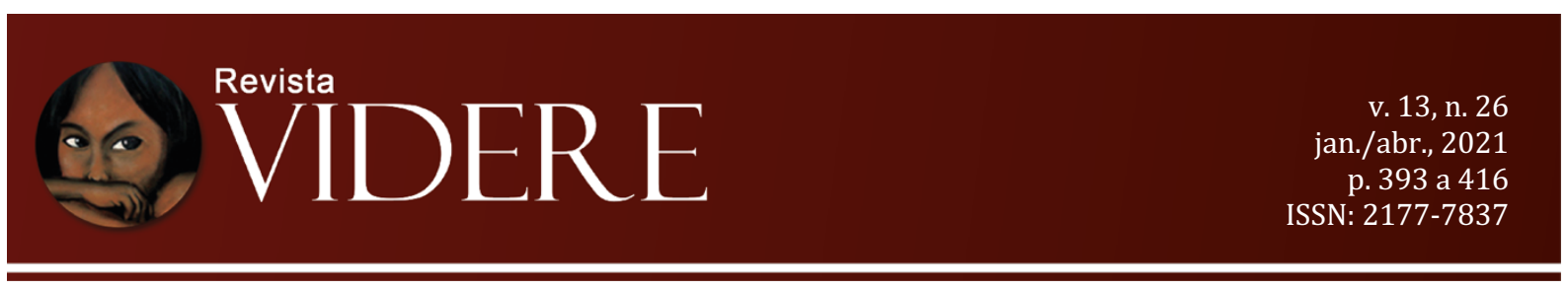

\title{
CONCEITOS INICIAIS DE RACISMO DISCURSIVO
}

\author{
INITIAL DISCURSIVE RACISM CONCEPTS
}

\author{
CONCETTI INIZIALE DI RAZZISMO DISCORSIVO
}

\section{Renata Almeida Danin}

Doutoranda em Comunicação pela Universidade de Brasília - UnB. Mestra em Segurança Pública pela Universidade Federal do Pará - UFPA. renatadanin@gmail.com OrcID: http://orcid.org/0000-0002-1243-7678

\begin{abstract}
Liliane Maria Macedo Machado Doutora em História pela Universidade de Brasília - UnB. Docente do Programa de Pós-Graduação em Comunicação da Universidade de Brasília -UnB. profliliane@globo.com OrcID: http://orcid.org/0000-0003-3143-4680
\end{abstract}

Resumo: Este trabalho busca explorar conceitos iniciais de racismo, enfatizando o racismo discursivo e a reprodução de ideologias de subalternidade na construção da imagem do negro na sociedade contemporânea. Utilizaremos como arcabouço teórico a perspectiva decolonial de diversos autores, entre eles: Grada Kilomba, Lélia Gonzalez, Frantz Fanon e o sociólogo Teun Van Dijk, especialista em Análise do Discurso. Utilizaremos a revisão bibliográfica como método principal neste trabalho.

Palavras-chave: Racismo. Racismo Discursivo. Análise do Discurso.

Abstract: This work seeks to explore initial concepts of racism, emphasizing discursive racism and the reproduction of subordinate ideologies in the construction of the image of the black in contemporary society. We will use as a theoretical framework the decolonial perspective of several authors, among them: Grada Kilomba, Lélia Gonzalez, Frantz Fanon and the sociologist Teun Van Dijk, specialist in Discourse Analysis. We will use the bibliographic review as the main method in this work.

Keywords: Racism. Discursive Racism. Speech Analysis.

Sommario: Questo lavoro cerca di esplorare i concetti iniziali del razzismo, enfatizzando il razzismo discorsivo e la riproduzione di ideologie subordinate nella costruzione dell'immagine 
del nero nella società contemporanea. Useremo la prospettiva decoloniale di diversi autori come cornice teorica, tra cui: Grada Kilomba, Lélia Gonzalez, Frantz Fanon e il sociologo Teun Van Dijk, specialista in Analisi del discorso. Useremo la revisione bibliografica come metodo principale in questo lavoro.

Parole chiave: Razzismo. Razzismo Discorsivo. Analisi del Discorso.

\title{
1 Introdução
}

\author{
Maria, Maria \\ É o som, é a cor, é o suor \\ $\dot{E}$ a dose mais forte e lenta \\ De uma gente que ri \\ Quando deve chorar \\ E não vive, apenas aguenta
}

Fernando Brant e Milton Nascimento

Segundo o sociólogo holandês Teun Van Dijk (2008), o discurso controla mentes e mentes controlam a ação. Isso significa que, para aqueles que estão no poder, é crucial controlar, em primeiro lugar, o discurso. Mas de que modo uma entonação específica, um pronome, uma manchete jornalística, um tópico, uma metáfora, uma cor ou um ângulo de câmera se relacionam a algo, aparentemente, tão abstrato e geral como as relações de poder na sociedade? Este trabalho busca analisar as formas de abuso de poder, manipulação, doutrinação e desinformação que resultam em desigualdade e injustiça social direcionada aos negros. Utilizaremos como instrumento a análise crítica do discurso proposta por Teun Van Dijk, que desenvolve ferramentas de análise e as aplica em exemplos concretos como notícias jornalísticas, livros didáticos e discursos políticos; além de mapear os possíveis danos a sociedade advindos desta prática discursiva que subalterniza o negro na sociedade brasileira.

Muitas vezes relacionada à filosofia da linguagem, a análise do discurso atua hoje como um amalgama metodológico dividido em diferentes escolas e tendências epistemológicas. O campo da análise do discurso é complexo e de caráter interdisciplinar, com bases desenvolvidas em disciplinas das ciências humanas e sociais, a exemplo da linguística, semiótica, literatura, antropologia, sociologia, teoria da comunicação, psicologia social e cognitiva e a própria inteligência artificial.

O campo jornalístico-informacional apresenta-se como um dos espaços mais importantes a ser ocupado pelo discurso, dada a dimensão pública que imprime aos debates e 
por constituir-se como referente social, especialmente nos casos das questões relativas ao racismo. Para Van Dijk (1991), o papel da imprensa na reprodução do racismo na sociedade não pode mais simplesmente ser avaliado listando temas estereotipados ou dando exemplos de tendências óbvias contra as minorias. A análise do discurso permite por meio da integração de diferentes disciplinas, estudar como as estruturas de poder, dominação e desigualdade dentro de uma sociedade são reproduzidas através do texto e da fala.

A metodologia de Análise Crítica do Discurso analisa um componente fundamental: o uso da linguagem, ressaltando aspectos cognitivos, modelos mentais, conhecimentos e demais representações. As estruturas sociais, comunicativas, históricas e culturais, quando representadas em determinados contextos, são relevantes para uma formação sociocognitiva, que pode vir a se transformar em atitudes, hábitos e a formação de pensamento. O Discurso, sendo percebido como prática social desempenha papel interessante na sociedade, sendo responsável pela transmissão de conhecimentos e ideologias, de modo que se torna útil o uso dessa ferramenta para estudar e analisar a reprodução do racismo, dominação e desigualdade social na sociedade contemporânea. Os discursos não se limitam apenas a uma dimensão verbal, possuem também dimensões não verbais, e levam em consideração a entonação, gestos, sons, imagens, entre outros aspectos multimodais. Devido a estas características, somadas a importância da mídia na reprodução de ideologias, sobretudo a ideologia das Elites Simbólicas, transmitidas, neste caso, por grandes conglomerados de mídia e sua visão de mundo.

As relações raciais no Brasil são objeto de discussão em diversos setores da sociedade: na academia, na mídia e na política. A ponto de chegarem a um consenso quanto a existência de desigualdades de cunho histórico, social e econômico, gerando então um grande debate no que diz respeito a solução dessas desigualdades, mesmo após pouco mais de um século da abolição da escravidão. O fato é que tais desigualdades seguem separando negros dos espaços de poder na sociedade contemporânea.

O discurso midiático na comunicação de massa tem um papel importante, pois a partir dele adquire-se informação, conhecimento e forma-se opinião. Deste modo, a comunicação de massa atua como um dos mais importantes meios de construção e reprodução de ideologias. Segundo Van Dijk (2008), não é qualquer concepção que é transmitida, mas sim a das elites simbólicas ou as denominadas elites dominantes: os verdadeiros fabricantes do conhecimento, dos padrões morais, das crenças, atitudes, normas, das ideologias e dos valores públicos.

Sendo assim, Van Dijk (2000) amplia a noção de racismo e a define como uma prática social de desigualdade étnico-racial e de gênero, expondo as inequidades baseadas nas classes sociais. A formulação desse conceito, desta ampliação do racismo e da formação do que ele 
atribui a um "novo racimo" está ligada a outro conceito crucial em nosso aporte teórico, o das "elites simbólicas". Estas elites têm o poder real de influenciar, de criar ideologias e de reproduzi-las, sendo responsáveis indiretas, e muitas vezes diretas, pela situação de desigualdade entre negros e brancos na sociedade ocidental moderna; são elites políticas, educacionais, escolares e midiáticas, que controlam o acesso à maioria dos discursos públicos respeitados pela sociedade.

Esse poder confere a essas elites um papel específico na reprodução de conceitos e valores, ou seja, na propagação do valor simbólico que envolve o tecido social, sendo responsável pela influência das configurações narrativas de racismo, justamente as formas que Van Dijk (2008) denomina como o "novo racismo". Estas formas, que atuam de maneira sutil e simbólica, que são expressas, legitimadas e confirmadas por textos e conversas, incluindo programas de TV e notícias em veículos diversos.

De acordo com Van Dijk (2008), produções simbólicas - como a mídia - de uma sociedade são ideológicas quando atuam para criar ou manter relações de dominação de indivíduos sobre outros, possibilitando acesso a bens materiais e culturais. Sabemos da necessidade de transformações estruturais para diminuir as desigualdades sociais e o racismo, pois os negros apresentam as maiores taxas de letalidade violenta, violência policial, encarceramento, além dos piores índices em educação, saúde, renda e moradia. É importante que as práticas culturais que mascaram, ocultam ou estereotipam o negro na sociedade sejam modificadas e o campo simbólico é um mero reflexo da realidade conjuntural e ajuda a produzir as condições estruturais.

Discurso e manipulação acontecem quando as elites simbólicas manipulam suas audiências por intermédio de algum tipo de influência discursiva ilegítima. Van Dijk (2000), associa esta manipulação ao abuso de poder e atenta para a necessária compreensão de que esse tipo de controle atravessa inicialmente o controle da mente das pessoas (por meio de crenças, conhecimentos, opiniões e ideologias) e assim, consequentemente, atinge o controle de suas ações. O ponto em que esta manipulação acontece é justamente no discurso, incluindo particularidades de cunho não verbal reproduzidas a partir de gestos, expressões faciais, cores, configurações textuais, imagens, sons, músicas e etc.

Desta forma a Análise do Discurso surge nas ciências humanas e sociais, provocando nos pesquisadores uma preocupação real com o abuso de poder e suas formas de dominação decorrentes da reprodução discursiva e da desigualdade social. Do ponto de vista metodológico, ela visa contribuir para o empoderamento social dos grupos dominados, expondo as disposições do discurso na interação e na organização social. Nesse sentido, Van Dijk (2000) explica que o 
discurso não é analisado apenas como um artefato verbal independente, mas também como uma interação construída, como uma prática social ou como um tipo de comunicação num contexto social, histórico ou político.

O principal método a ser utilizado neste trabalho será a revisão bibliográfica, a partir deste método revisitaremos conceitos importantes sobre racismo e racismo narrativo. Todos os autores presentes dialogarão entre si a partir da perspectiva decolonial. Alguns exemplos de Análise do Discurso Crítica serão demonstrados, para que seja possível visualizar a aplicação prática do método no dia a dia.

O referencial teórico deste trabalho começa com a história mais básica e elementar dos livros de história, a escravidão. De acordo com a linha do tempo (figura 1), observa-se que foram trezentos anos de tráfico negreiro e trezentos e trinta e oito anos até a abolição da escravatura no Brasil (o último país a fazê-lo). Esse processo colonial e escravocrata, deixou sequelas em nossa sociedade e hoje isso é observado em diversas estatísticas relacionadas a índices sociais e de desenvolvimento humano, temas como acesso à educação, a saúde, moradia, emprego e renda, que sempre deixam o sujeito negro à margem.

Enquanto um homem negro é assassinado a cada 21 minutos, ou tem 2.7 vezes mais chances de ser morto em relação a um homem branco, negros também possuem mais chances de sofrer violência durante uma abordagem policial e são maioria entre os encarcerados (WAISELFISZ, 2016). Mulheres negras são as maiores vítimas de violência obstétrica, estão sobrerepresentadas em empregos de nível operacional e também são maioria entre moradores de favelas, e por viverem em locais distantes da presença do Estado tem baixíssimos índices de acesso a saúde (postos de saúde), educação (escolas, creches) e lazer (centros esportivos, centros culturais, parques), um sistema cruel, que se retroalimenta dos resquícios coloniais e racismos ainda persistentes em nossa sociedade, e que serão melhor abordados ao longo deste trabalho. 
Figura 1: A escravidão negra no Brasil

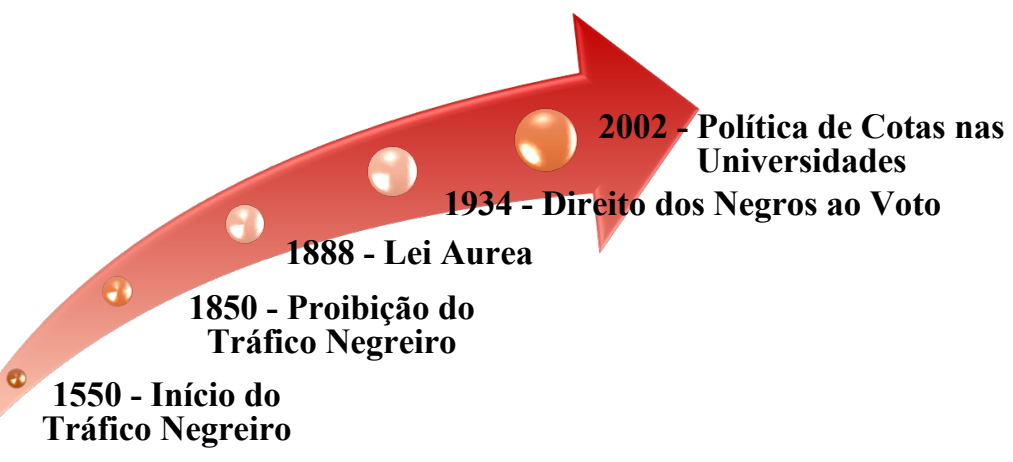

Fonte: elaborado pela autora.

O Brasil é o país do carnaval, da mulata e do futebol. Estereótipos conhecidos em que a figura do negro ocupa lugar de destaque. Sempre atrelado a cena folclórica e pouco citado no campo intelectual, político e ausente em profissões tradicionais (juízes, médicos, professores universitários, engenheiros e etc.) de grande destaque na sociedade. Consequências advindas de três séculos de escravidão e uma abolição tardia. Em muitas ocasiões, os casos de discriminação racial são frequentes e vão desde manifestações racistas em universidades de elite contra estudantes cotistas, morte de pessoa negra a socos e pontapés em estacionamento de supermercado, às estatísticas que indicam que mais de $70 \%$ das vítimas de homicídios são negros (CERQUEIRA, 2014). Atualizando a discussão para os tempos de pandemia da COVID19 no mundo, negros encontram-se também entre os grupos mais expostos, pois possuem empregos com pouca projeção intelectual (consequência da baixa escolaridade) que não se admite a realização de teletrabalho (em sua maioria), e passam a se expor aos riscos do transporte público em grandes cidades, empregos que necessitam contato direto com o público externo (faxineira, gari, atendente, feirante, motorista e etc.) ou mesmo amargam o desemprego e dificuldade de acesso a planos de saúde, medicamentos, alimentação e demais formas efetivas de tratamento. Encontrando-se em situação de vulnerabilidade ainda maior neste novo cenário sanitário mundial.

É verdade que muito foi feito nos últimos anos para que essa dívida histórica remanescente da escravidão fosse recompensada: como a criação da política de cotas para afrodescendentes em vestibulares e concursos públicos, a criação do estatuto da igualdade racial, promulgado em 2010 e a própria Lei 7.437/1985 que criminaliza atos resultantes de preconceito racial, além de medidas diversas nos mais diversos âmbitos sociais. Ainda assim 
esses mecanismos não foram suficientes para uma melhoria real ou diminuição de desigualdades entre negros e brancos, por isso precisamos mergulhar nos conceitos para compreender a real dimensão do problema. Uma teoria recente sobre a influência racial, tons de pele e hierarquia, nos trouxe a ideia de que há uma pigmentocracia que atua como uma espécie de hierarquia racial e nos apresenta brancos no topo da pirâmide, mestiços no meio e negros e indígenas na base (TELLES, 2014). Abaixo temos a paleta de cores extraída do livro Pigmentocracies (2014), que determina onze cores possíveis para classificação racial, sendo a número um, branca, e a número onze, negra. Esta paleta serviu de base e tornou a pesquisa um tanto quanto objetiva, no sentido de que cada pesquisador auferia a cor de cada participante de acordo com a tabela, dessa forma eliminava-se o fator subjetivo, que faria com que pessoas que tem a mesma cor da pele escolhessem estratos de cores diferentes para se auto identificar. A exemplo de pessoas negras que na auto identificação se caracterizam como pardas, por exemplo. Com o uso das paletas a pesquisa pode ser melhor conduzida e ter resultados mais fidedignos.

Figura 2: Paleta de Cores extraída do livro Pigmentocracies (2014)

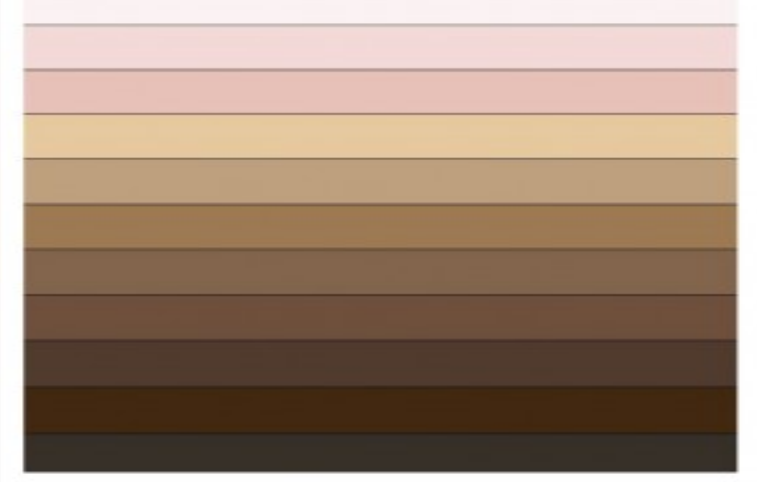

Fonte: adaptado de Telles (2014).

Telles (2014) demonstra que por trás de todas as camadas raciais, em todos os países da América Latina, há uma graduação de cor e os sujeitos de pele mais clara, eventualmente, possuem melhor posição financeira e social do que os de pele mais retinta, e os indivíduos com tons de pele intermediária encontram-se numa situação financeira e social mediana. Para Telles (2014), desigualdades sociais e econômicas baseadas em raça e etnia também estão começando a ser reconhecidas. Em 1944 o antropólogo chileno Alejandro Lipschutz, cunhou o termo pigmentocracia, que indica que, na América Latina as hierarquias sociais são baseadas na cor ou etnia. A ideia foi ignorada até recentemente, quando pesquisas usando novos dados do censo sobre identificação racial começaram a documentar as desigualdades raciais. Esses estudos 
geralmente mostram que os afrodescendentes e indígenas ocupam os degraus mais baixos nas escalas de renda, educação e ocupação em toda a América Latina.

O Racismo está por trás de todas as problemáticas supracitadas, é uma chaga dos tempos coloniais que internalizou diversos fatores predominantes na formação da nossa sociedade e estabeleceu o homem branco como "padrão" e o sujeito negro como o "outro". Neste trabalho iremos conceituar algumas formas de racismo, para que possamos compreender e analisar os discursos de forma crítica e sob a ótica correta. Existe uma infinidade de racismos em nossa sociedade e toda vez que a sociedade se atualiza as formas de racismo também se atualizam e adquirem novas configurações, de modo que apresentaremos abaixo apenas um apanhado com os tipos mais comuns.

\section{Quadro 1 - Tipos de Racismos}

\begin{tabular}{|c|c|}
\hline Racismo & $\begin{array}{l}\text { O racismo pode ser definido como a qualidade de decisões e políticas, que levam em } \\
\text { consideração a raça, com o objetivo de subordinar um grupo racial e manter o controle sobre } \\
\text { este grupo (WIEVIORKA, 2007). }\end{array}$ \\
\hline $\begin{array}{l}\text { Racismo } \\
\text { Cotidiano }\end{array}$ & $\begin{array}{l}\text { O termo "cotidiano" refere-se ao fato de que essas experiências não são pontuais. O } \\
\text { racismo cotidiano não é um "ataque único" ou um "evento discreto", mas sim uma } \\
\text { "constelação de experiências de vida", uma "exposição constante ao perigo", um "padrão } \\
\text { contínuo de abuso" que se repete incessantemente ao longo da biografia de alguém, no ônibus, } \\
\text { no supermercado, em uma festa, no jantar, na família (KILOMBA, 2019, p. 77). }\end{array}$ \\
\hline $\begin{array}{l}\text { Racismo } \\
\text { Estrutural }\end{array}$ & $\begin{array}{l}\text { O racismo revela-se em um nível estrutural, quando pessoas negras e pessoas de cor } \\
\text { estão excluídas da maioria das estruturas sociais e políticas. Estruturas oficiais operam de uma } \\
\text { maneira que privilegia manifestadamente seus sujeitos brancos, colocando membros de outros } \\
\text { grupos racializados em uma desvantagem visível, fora das estruturas dominantes. Isso é } \\
\text { chamado de racismo estrutural (KILOMBA, 2019, p. 77). }\end{array}$ \\
\hline $\begin{array}{l}\text { Racismo } \\
\text { Institucional }\end{array}$ & $\begin{array}{l}\text { Como o termo "instituição" implica, o racismo institucional enfatiza que o racismo } \\
\text { não é apenas um fenômeno ideológico, mas também institucionalizado. O termo se refere a } \\
\text { um padrão de tratamento desigual nas operações cotidianas tais como em sistemas e agendas } \\
\text { educativas, mercados de trabalho, justiça criminal, etc. O racismo institucional opera de tal } \\
\text { forma que coloca os sujeitos brancos em clara vantagem em relação a outros grupos } \\
\text { racializados (KILOMBA, 2019, p. 77). }\end{array}$ \\
\hline
\end{tabular}




\begin{tabular}{|l|l|}
\hline $\begin{array}{l}\text { Racismo } \\
\text { Discursivo }\end{array}$ & $\begin{array}{l}\text { Elites políticas, educacionais, escolares e midiáticas controlam o acesso à maioria } \\
\text { dos discursos públicos respeitados pela sociedade. Atuam na reprodução de conceitos, valores } \\
\text { e na propagação do valor simbólico que envolve o tecido social, sendo responsáveis pela } \\
\text { influência das configurações discursivas de racismo (VAN DIJK, 2000). }\end{array}$ \\
\hline
\end{tabular}

Fonte: adaptado pela autora com base em Kilomba (2019), Van Dijk (2000) e Wieviorka (2007).

Van Dijk (2008) alerta que as desigualdades no tratamento relacionado aos indígenas e negros na sociedade atual têm sido atribuídas à classe social e não à questão racial, sem que se investigue de fato as raízes das desigualdades de classe e renda. A lógica racial é importante para explicar essas desigualdades, por isso utilizamos o conceito de racismo elaborado pelo sociólogo holandês:

\begin{abstract}
Racismo é essencialmente um sistema de dominação e desigualdade social. Na Europa, nas Américas e na Austrália, isso significa que uma maioria (e, às vezes, uma minoria) "branca" domina minorias não europeias. A dominação, por sua vez, se define como um abuso de poder de um grupo sobre outro e está representada por dois sistemas inter-relacionados de práticas sociais e cognitivas diárias: de um lado, por várias formas de discriminação, marginalização, exclusão ou problematização; do outro, por crenças, atitudes e ideologias preconceituosas e estereotipadas. Estas últimas podem ser consideradas, de muitas maneiras, "razões" ou "motivos" para explicar ou legitimar as primeiras (VAN DIJK, 2015, p. 33).
\end{abstract}

Segundo Van Dijk (2008), a definição do que é racismo vai além da ideologia racista. É um sistema social complexo de dominação, que envolve fundamentos éticos e desigualdades, além de ser estruturado por um sistema social e cognitivo. Esse sistema envolve práticas sociais de discriminação em nível micro (local) e macro (grupos, organizações e instituições dominantes).

Há uma assimetria de grupos no poder, há também assimetria no acesso que os grupos têm a recursos necessários para implementar suas próprias vozes (Collins, 2000). É por isso que o resultado do trabalho de intelectuais negros permanece, de um modo geral, fora do corpo acadêmico. Porém, eles não estão neste lugar de forma acidental, eles foram colocados a margem por quem domina e regula o que é a "verdadeira" erudição. Isso é uma característica marcante da colonização, que foi além da autoridade ocidental sobre terras, modo de produção e governos indígenas, mas acima de tudo, a imposição ocidental sobre o saber, língua e cultura, por isso é urgente a necessidade de descolonizar a ordem eurocêntrica do conhecimento (Kilomba, 2019). Logo, na academia, não há uma verdade científica, mas sim o resultado de relações díspares de poder racial, mais uma faceta do racismo.

Qualquer forma de saber que não se enquadre na ordem eurocêntrica de conhecimento tem sido continuamente rejeitada, sob o argumento de não constituir ciência credível. A ciência não é, nesse sentido, um simples estudo apolítico da verdade, mas a reprodução de relações 
raciais de poder que ditam o que deve ser considerado verdadeiro e em quem acreditar. Os temas, paradigmas e metodologias do academicismo tradicional, a chamada epistemologia, refletem não um espaço heterogêneo para a teorização, mas sim os interesses políticos específicos da sociedade branca (KILOMBA, 2019, p. 55).

No racismo, corpos negros são construídos como corpos impróprios, como corpos que estão "fora do lugar" e por essa razão, corpos que não podem pertencer. Corpos brancos ao contrário, são construídos como próprios, são corpos que "estão no lugar", "em casa", corpos que sempre pertencem (Kilomba, 2019).

Nesta dualidade entre pertencer e estar fora do lugar, encontram-se várias formas de perceber o sujeito negro, esta percepção é muito comum também no discurso midiático, na literatura, no cinema, na música e em diversas narrativas ainda muito usadas em nosso dia a dia, por isso é necessário identificá-las no discurso para que possamos combatê-las. É possível identificar algumas das principais formas logo abaixo:

\section{Quadro 2 - Formas de Percepção do Sujeito Negro}

\begin{tabular}{|l|l|}
\hline Infantilização & $\begin{array}{l}\text { O sujeito negro torna-se a personificação do dependente, do menino, do servo, do que não } \\
\text { pode sobreviver sem o "senhor". }\end{array}$ \\
\hline Primitivização & $\begin{array}{l}\text { O sujeito negro torna-se a personificação do incivilizado, o selvagem, o atrasado, o básico, o } \\
\text { natural, aquele que está mais próximo da natureza. }\end{array}$ \\
\hline Incivilização & $\begin{array}{l}\text { O sujeito negro torna-se a personificação do outro, do violento, ameaçador, criminoso, } \\
\text { suspeito, perigoso, daquele que está fora da lei. }\end{array}$ \\
\hline Animalização & O sujeito negro torna-se a personificação do animal, do selvagem, do primata, do macaco. \\
\hline Erotização & $\begin{array}{l}\text { O sujeito negro torna-se a personificação do sexualizado, com um apetite sexual violento, a } \\
\text { prostituta, o cafetão, o estuprador, a erótica, o exótico. }\end{array}$ \\
\hline
\end{tabular}

Fonte: Elaborado pela autora com base em Kilomba (2019).

A estrutura racial imposta, engendrada pela branquitude europeia colonizadora, criou um lugar para o sujeito negro e o despersonalizou.

A ideia de que pessoas negras são sempre colocadas como o outro e nunca como o eu, pressupõe uma ideia de perda, pois no racismo o indivíduo é retirado e violentamente separado de qualquer identidade que ele possa realmente ter. Tal separação é definida como um trauma clássico, uma vez que priva o indivíduo de sua própria conexão com a sociedade inconscientemente pensada como branca (FANON, 1967, P.112).

Pessoas negras sempre tem sua vida pautada pela questão racial em todos os momentos, a cor da pele é sempre uma condição ou um fator de impacto que nunca passa incólume. "Quando pessoas gostam de mim, dizem que é apesar da minha cor. Quando não 
gostam de mim, apontam que não é por causa da minha cor. Em ambas as situações, não tenho saída" (FANON, 1967, P.116).

\section{Elites Simbólicas}

Conforme afirmamos anteriormente, nosso arcabouço teórico tem um caminho atrelado as ideias do sociólogo Teun A Van Dijk, pois ele já traçou em diversos trabalhos anteriores as características e abordagens do que ele chama de novo racismo ou racismo discursivo, e a partir da narrativa e da análise crítica do discurso, iremos expor, analisar e problematizar a influência das elites simbólicas e as consequências desta exposição na construção da imagem do sujeito negro. Deste modo, iremos agora discutir o que são as elites simbólicas e porque elas têm um papel tão importante na construção atual e no modo que enxergamos a negritude em nossa sociedade de um modo geral.

As elites simbólicas são elites que, literalmente, têm tudo 'a dizer' na sociedade, assim como suas instituições e organizações. Seus membros podem ser professores, jornalistas, acadêmicos, políticos, escritores, etc. (VAN DIJK, 2008, p. 235). As elites simbólicas mantêm relações de abuso discursivo de poder, isto é, mantêm relações de dominação. A manipulação é um fenômeno social, porque a interação e abuso de poder ocorrem entre grupos e atores sociais por causa da posição social que ocupam, e trata-se de um fenômeno de cunho cognitivo porque exerce influência nas mentes das pessoas, por meio da escrita, fala ou imagens (VAN DIJK, 2008, p. 236).

Sabemos que o racismo é aprendido e na maior parte das vezes é legitimado pelas vias do discurso, de modo que as ideologias e demais preconceitos não nascem com as pessoas, eles são aprendidos, adquiridos ao longo do tempo e tem como principal porta de acesso a comunicação (escrita, falada e etc.). Estas representações mentais do racismo são legitimadas no discurso e assim reproduzidas e compartilhadas dentro do grupo dominante, que então compartilha essa visão com a sociedade.

Por isso o foco do trabalho de Van Dijk é estudar as manifestações mais sutis de racismo, aquelas que as elites se recusam em chamar de racistas, ao invés das manifestações mais abertas, que são tidas como o real racismo, mas que não são socialmente aceitas ou respeitáveis (VAN DIJK, 1991, p. 11).

Ao tratar o racismo apenas como uma questão explícita, focalizando apenas os casos mais radicais e escancarados, se favorece as elites simbólicas, à medida que negam o seu próprio racismo e as deixamos de fora do problema. Porém, observando o histórico do racismo 
ocidental e analisando as experiências de minorias, percebe-se que as formas de racismo praticadas pelas elites simbólicas são ainda mais sérias, pois geram consequências negativas a longo prazo, pois ficam internalizadas no campo cognitivo das pessoas.

Por isso buscamos no texto, traços dos discursos que criam e que continuam trabalhando para a manutenção de narrativas racistas, mesmo que pouco perceptível, ou seja, é papel do analista do discurso averiguar o dispositivo de expressão que liga certa disposição textual a um lugar social determinado.

Poderosos são os meios de comunicação de massa para a formação da opinião pública, principalmente quando conseguem atingir um maior número de leitores. Não há dúvida de que, dentre todas as formas de texto impresso, as dos meios de comunicação de massa são as mais penetrantes, se não as mais influentes, a se julgar pelo poder baseado no número de receptores (VAN DIJK, 2008, p. 73).

Nesse sentido, ao discorrer sobre formas atuais de racismo Van Dijk explora a dimensão discursiva do "novo racismo", baseando-se em sua natureza simbólica. Portanto, concebe-se esse racismo como um sistema que possui dois componentes principais: o social e o cognitivo. O componente social consiste nas práticas cotidianas de discriminação, no micro nível de análise. E as instituições, organizações, arranjos legais, bem como, outras estruturas sociais, no macro nível. O discurso racista pertence à dimensão institucional. Porém, as práticas sociais estão imbuídas pela dimensão cognitiva, as quais envolvem as crenças, o pensamento, as ideologias, as normas e os valores. Os estereótipos racistas, preconceitos e ideologias são adquiridos e aprendidos, e isso, normalmente, ocorre por meio da comunicação discursiva, ou seja, escrita e falada. As práticas discriminatórias nas quais as pessoas se engajam, são justificadas, principalmente, pelo pensamento de que os "diferentes" são inferiores, possuem menos direitos, ou prioridades (VAN DIJK, 2008, p. 105).

Deste modo é possível compreender como ocorre a manutenção desse sistema de dominação sobre o outro:

Os atores sociais mais poderosos são aqueles que possuem os meios e recursos para influenciar as ações e mentes de outros. Tal controle é tipicamente exercido pelo fornecimento de informação limitada, errada ou enviesada sobre determinado evento para recipientes que não possuem acesso a fontes alternativas de informação e que, generalizando a partir desse modelo, formarão novos modelos mentais enviesados reproduzindo percepções e ações de acordo. A dominação discursiva, portanto, pode ser definida como o controle comunicativo do conhecimento, crenças e opiniões daqueles que possuem poucos recursos e fontes alternativas para se opor a tal influência" (VAN DIJK, 1991, p. 101). 
Foucault (1979) explica que os discursos da sociedade, por meio da linguagem, comportamentos e valores, são relações de poder e por isso aprisionam os sujeitos. Cada sociedade tem sua verdade e os tipos de discursos que aceita como verdadeiros, os meios pelo qual cada um deles é aceito, as técnicas e procedimentos valorizados na aquisição da verdade, e quem está encarregado de dizer o que é verdade. Por isso, Foucault vê na linguagem uma forma já estabelecida na sociedade.

Essa verdade levantada por Foucault, nos faz refletir quanto a quem tem a legitimidade do discurso, quem pode falar? Quem fala a verdade? E quem pode ser ouvido?

\section{Quem pode falar?}

Os conceitos de conhecimento, erudição e ciência estão intimamente ligados ao poder e a autoridade racial. Grada Kilomba (2019) propõe as seguintes perguntas e tenta elucidá-las a partir das respostas, percebendo então que, até mesmo o centro acadêmico não é um lugar neutro. Ele é um espaço branco (principais teóricos, principais teorias, a maioria dos professores universitários, eixo geográfico onde as pesquisas são produzidas e etc.) onde o privilégio da fala tem sido negado para pessoas negras. E temos aqui mais um exemplo da ação de uma elite simbólica e de uma narrativa.

\section{Quadro 3 - Quem pode falar?}

\begin{tabular}{|l|l|}
\hline \multicolumn{1}{|c|}{ Sujeito Branco } & \multicolumn{1}{|c|}{ Sujeito Negro } \\
\hline Qual conhecimento está sendo reconhecido como tal? & E qual conhecimento não o é? \\
\hline $\begin{array}{l}\text { Qual conhecimento tem feito parte das agendas } \\
\text { acadêmicas? }\end{array}$ & E qual conhecimento não? \\
\hline $\begin{array}{l}\text { Quem é reconhecido como alguém que possui } \\
\text { conhecimento? }\end{array}$ & E quem não o é? \\
\hline Quem pode ensinar conhecimento? & E quem não pode? \\
\hline Quem está no centro acadêmico? & Quem permanece as margens? \\
\hline
\end{tabular}

Fonte: Elaborado pela autora com base em Kilomba (2019).

Para Kilomba (2019), historicamente, o espaço acadêmico, é um espaço onde pessoas negras têm estado sem voz, onde acadêmicos brancos têm desenvolvido discursos teóricos que formalmente constroem o "outro" como inferior, colocando africanos em subordinação absoluta ao sujeito branco. Nesse espaço pessoas negras têm sido descritas, classificadas, 
desumanizadas, primitivizadas, brutalizadas e mortas. Espaços os quais o tema da negritude é posto como "objeto" de discursos estéticos e culturais da branquitude, nunca como "sujeitos".

Tal posição de objetificação que comumente ocupamos, esse lugar da "outridade" não indica, como se acredita, uma falta de resistência ou interesse, mas sim a falta de acesso à representação, sofrida pela comunidade negra. Não é que nós não tenhamos falado, o fato é que nossas vozes, graças a um sistema racista, têm sido sistematicamente desqualificadas, consideradas conhecimento inválido, ou então representadas por pessoas brancas que, ironicamente, tornam-se "especialistas" em nossa cultura, e mesmo em nós (KILOMBA, 2019, p.51).

De ambos os modos, é possível afirmar que a academia não é um espaço neutro nem tampouco simplesmente um espaço de conhecimento e sabedoria, de ciência e erudição, é também um espaço de violência (Kilomba, 2019).

A ideia de que o trabalho acadêmico desenvolvido por pessoas negras é interessante, mas não muito científico, ilustra a ordem colonial na qual intelectuais negros residem: "você tem uma perspectiva demasiado subjetiva", "muito pessoal", "muito específico", "esses são fatos objetivos?". Tais comentários funcionam como uma máscara que silencia nossas vozes assim que falamos. Eles permitem que o sujeito branco posicione nossos discursos de volta nas margens, como conhecimento desviante, enquanto seus discursos se conservam no centro, como a norma. Quando eles (brancos) falam é científico, quando nós (negros) falamos é acientífico (KILOMBA, 2019, p. 52).

Quadro 4 - Conhecimento e o mito do universal

\begin{tabular}{|l|l|}
\hline \multicolumn{1}{|c|}{ Sujeito Branco } & \multicolumn{1}{c|}{ Sujeito Negro } \\
\hline Conhecimento Universal & Conhecimento Específico \\
\hline Conhecimento Objetivo & Conhecimento Subjetivo \\
\hline Conhecimento Neutro & Conhecimento Pessoal \\
\hline Conhecimento Racional & Conhecimento Emocional \\
\hline Conhecimento Imparcial & Conhecimento Parcial \\
\hline Eles têm fatos & Nós temos opiniões \\
\hline Eles têm conhecimento & Nós temos experiências \\
\hline
\end{tabular}

Fonte: Elaborado pela autora com base em Kilomba (2019). 
Kilomba (2019) argumenta que estas categorizações semânticas possuem uma dimensão de poder que mantém posições hierárquicas e preservam o privilégio branco. De modo que se determina claramente quem, de facto, pode falar e ser ouvido.

Lélia Gonzalez (1988) estudou as manifestações de racismo na América Latina e trouxe algumas classificações importantes para nossa discussão, ela acredita que o racismo se expressa de duas formas diferentes, a depender da origem predominante em cada país.

Racismo Aberto: Característico das sociedades anglo-saxônicas, germânica ou holandesa, essa expressão do racismo considera negra qualquer pessoa que tenha tido antepassados negros. A miscigenação não é algo que seja considerado (embora a mulher negra tenha sido sempre explorada sexualmente pelos donos da casa-grande), uma vez que o grupo branco quer manter a "pureza" e reafirmar sua "superioridade". Nos Estados Unidos, por exemplo, existe o fenômeno do one drop rule ou regra da gota única, que diz que qualquer pessoa, mesmo com um único ancestral de ascendência africana, será considerada negra. É importante ressaltar que se trata de um princípio legal de classificação racial e está restrito aos Estados Unidos. Embora recentemente, após mudanças no censo americano, os americanos podem se classificar racialmente da maneira que quiserem, inclusive podendo escolher mais de uma raça, isso é fruto de uma mudança de mentalidade ao longo dos anos, resultante de processos imigratórios e até mesmo casamentos inter-raciais. A título de curiosidade, as classificações raciais mais usadas pelos cidadãos americanos miscigenados são: mixed-race (mestiço), biracial (birracial) ou multiracial (multirracial).

Racismo Disfarçado: Se expressa nas sociedades de origem latina, podendo ser chamado também de racismo por denegação. Nesse caso, prevalecem as teorias da miscigenação, da assimilação e da democracia racial. "A chamada América Latina que, na verdade, é muito mais ameríndia e amefricana do que qualquer outra coisa, apresenta-se como o melhor exemplo de racismo por denegação" (GONZALES, 1988, pg. 72).

Gonzalez conclui que o fato de Espanha e Portugal terem adquirido uma vasta experiência na articulação das relações raciais (em grande medida pela presença moura e as disputas que dela decorreram) explica porque o racismo por degeneração tem grande expressão na América Latina. Para ilustrar essa articulação, a autora cita o antropólogo Roberto Da Matta, que explica que as sociedades que formam a América Latina herdaram as ideologias de classificação social (racial e sexual) e as técnicas jurídicas das metrópoles ibéricas. Segundo o autor, essas sociedades, por serem hierarquizadas e racialmente estratificadas, não precisaram utilizar-se de formas abertas de segregação, pois a própria hierarquia garante a superioridade dos brancos enquanto grupo dominante (DA MATTA, 1984). 
Segundo Gonzalez (1988), as sociedades onde o racismo disfarçado se expressa, é fortemente marcada pela ideologia do branqueamento. De acordo com essa categoria, o racismo mantém, de forma sofisticada, negros e indígenas na condição de subordinados dentro das classes mais exploradas. Os valores do Ocidente branco são os únicos verdadeiros e universais. O mito da superioridade branca fragmenta a identidade racial, produzindo o desejo das pessoas negras em embranquecer.

E apesar de todo o arcabouço teórico aqui demonstrado, que expõe as mazelas do racismo, que perpassam em todos os pontos da vida do sujeito negro, ainda assim acredita-se na possibilidade de mudança, que surge a partir da consciência, o sujeito branco tem um papel fundamental neste quesito e a capacidade de ouvir é o primeiro passo em busca dessa desconstrução. Embora não seja tarefa fácil, ainda assim há uma abordagem psicanalítica que suporta esse processo. $\mathrm{O}$ intuito desse trabalho, além de apontar o problema é também de sugerir alternativas para uma solução futura.

Paul Gilroy (1987), descreve cinco mecanismos distintos de defesa do ego pelos quais o sujeito branco passa a fim de ser capaz de ouvir, isto é, para que possa se tornar consciente de sua própria branquitude e de si próprio como perpetrador do racismo: negação, culpa, vergonha, reconhecimento e reparação.

\section{Figura 3 - Mecanismos de Defesa do Ego do Sujeito Branco até a Capacidade de Ouvir}

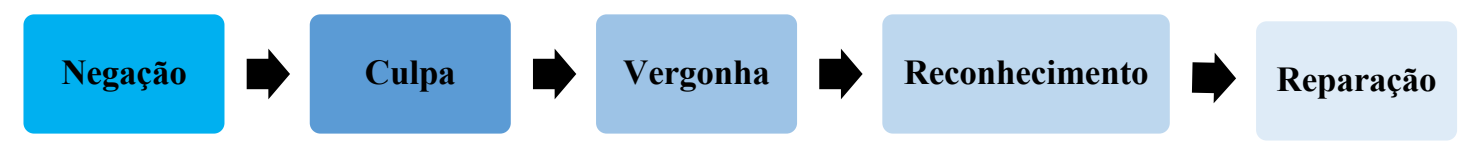

\begin{tabular}{|c|l|}
\hline Negação & $\begin{array}{l}\text { Recusa em admitir os aspectos mais desagradáveis da realidade externa, bem como } \\
\text { sentimentos e pensamentos internos. } \\
\text { Sujeito Branco: a informação é refutada e logo em seguida projeta-se aspectos } \\
\text { negativos sobre o "outro". "Eu não sou racista, mas..." } \\
\text { Sujeito Negro: "Eu nunca experienciei o racismo". Para diminuir a tristeza e o choque } \\
\text { emocional. }\end{array}$ \\
\hline Culpa & $\begin{array}{l}\text { É vivenciada em relação a um ato já cometido, ou seja, o racismo já aconteceu, criando } \\
\text { "Nós não queríamos dizer isso nesse sentido", "Você entendeu mal", "Não existe } \\
\text { brancos ou negros, somos todos humanos." }\end{array}$ \\
\hline Vergonha & $\begin{array}{l}\text { Ao perceber que a branquitude é vista como privilégio para o "outro" é possível } \\
\text { reconhecer a discrepância entre a percepção do outro e a própria percepção de si mesmo. } \\
\text { A vergonha é o resultado desse conflito. } \\
\text { Quem sou eu? Como os outros me percebem? O que represento para eles? }\end{array}$ \\
\hline Reconhecimento & $\begin{array}{l}\text { É o momento em que o sujeito branco reconhece a sua própria branquitude ou racismo } \\
\text { e aceita a percepção a realidade do "outro". }\end{array}$ \\
\hline
\end{tabular}


Reparação

Fonte: elaborado pela autora com base em Paul Gilroy (1987) adaptado por Kilomba (2019).
Reparar o mal causado pelo racismo através da mudança de estruturas, agendas, espaços, posições, dinâmicas, vocabulários, ou seja, através do abandono de privilégios.

Os passos acima citados revelam a consciência sobre o racismo, não como uma questão moral, mas como um processo psicológico que exige trabalho. Ou seja, ao invés de se questionar: eu sou racista? E esperar uma resposta confortável, o sujeito branco deveria se perguntar: como eu posso desmantelar meu próprio racismo? Tal pergunta, então, por si só, já inicia esse processo (KILOMBA, 2019, p.46).

\section{Discurso como forma de controle}

Para uma correta Análise Crítica do Discurso, além da análise da estrutura narrativa, é preciso analisar também as estruturas do contexto, ou seja, os parâmetros principais da situação comunicativa, e como é percebida pelos componentes no contexto social. A manipulação da narrativa é expressa através do controle do discurso público, controlando indiretamente o que o público deseja, de tal forma que o controle do discurso é uma forma de poder simbólico (VAN DIJK, 2008).

A Elite Simbólica é constituída por políticos, jornalistas, professores e toda sorte de profissionais que detém poder simbólico suficiente para controlar o discurso público, nas mais diversas dimensões semióticas. Por esse motivo, a análise do discurso está associada a uma análise social e a um abuso de poder, o poder simbólico. Ainda segundo Van Dijk (2008) as Elites Simbólicas, além de controlar as ações comunicativas, controlam também o pensamento dos demais. Isso se deve ao fato, de que o conhecimento adquirido através destas Elites ajuda a construir opiniões e atitudes. Mas dependendo do nível de conhecimento e reflexão do indivíduo, é possível rejeitar as ideias destas elites, mesmo que elas estejam em situação de poder. É importante frisar, que a propagação de ideologias, o controle da mente e a formação da opinião, é adquirida a partir da sociocognição, esta por sua vez, ponto forte no pensamento do sociólogo holandês Teun Van Dijk, e a grande responsável pela formação de opiniões, cultura e forma de pensar na atualidade, que molda o leitor a partir da visão de quem controla o discurso público.

É possível relacionar o papel das Elites Simbólicas propostas por Teun Van Dijk, com algumas características das Redes de Manuel Castells, uma vez que as redes concentram os legítimos reprodutores dos códigos de conhecimento, contribuindo com a construção da 
percepção coletiva (CASTELLS, 2000). Logo, ao ajudar a contribuir com a percepção coletiva, exerce-se também uma forma de poder simbólico. De modo que Van Dijk e Castells também se relacionam nas definições de poder, pois para Castells (2000) o poder é baseado no controle da comunicação e da informação, seja ela o macropoder do Estado e conglomerados de mídia ou o micropoder de organizações de todos os tipos.

De forma fluida e pouco perceptível, é possível a materialização de processos de aquisição racismo como uma relação de poder de um grupo sobre outro, assumindo a força das elites simbólicas no controle do discurso público. Também é possível afirmar que a ideologia com indícios de racismo, de um modo geral, se organiza a partir da representação positiva de si e representação negativa do outro. Podendo também ser utilizada a estrutura de nós versus eles, conceitos que podem ser aplicados em todos os níveis semânticos (imagens, tópicos e metáforas) e assim através da sociocognição engendrar um pensamento preconceituoso contra determinados grupos desprivilegiados socialmente, a exemplo dos negros e pobres de nossa sociedade (VAN DIJK, 2008).

\section{Racismo como violência simbólica}

O Racismo Institucional, racismo sutil, difuso, praticado por instituições de nossa sociedade, que em muitos casos não é perceptível devido seu caráter simbólico, e muitas vezes implícito no discurso público, aproxima-se das ideias do sociólogo Pierre Bourdieu, que nos ajuda a compreender importantes conceitos em nosso aporte teórico, como os de Dominação e Violência Simbólica.

A dominação não ocorre em decorrência direta da ação de uns sobre outros, mas a consequência indireta de ações que se produzem na estrutura do campo, que exerce predomínio em relação aos outros. Tal dominação não é manifesta, e sim disfarçada, a tal ponto que, muitas vezes, os que sofrem não a entendem (BOURDIEU, 2005).

\footnotetext{
"A violência simbólica incide em um abuso que se pratica com a conivência implícita dos que a toleram e também, com constância, dos que a praticam, de modo que alguns são inconscientes de que estão praticando ou sofrendo esta violência. Logo, a violência simbólica é uma violência velada, conferindo poderes. Tal violência não pode ser usada involuntariamente, pois não é um tipo distinto de violência. Ela é violência física disfarçada, camuflada e encoberta (BOURDIEU, 2005, p. 22).
}

Esse tipo de violência tem por consequência, instituir a legalidade de um discurso, de autorização, de uma instituição, porém as relações de poder que causam a violência simbólica são ignoradas (BOURDIEU, 2005). 
Logo, o racismo, sobretudo o racismo institucional, se comporta como uma espécie de violência simbólica, que é difundida em nossa sociedade através de diversas práticas, seja de forma explícita, direta, institucional, discursiva, por meio do não acesso a direitos, como educação, acesso à saúde, violência policial, representação negativa ou inexpressiva na mídia (DANIN, 2018).

\section{Exemplos de Racismo Narrativo}

Para Van Dijk (2008), corpus é uma coleção de textos compilados, em um mesmo idioma, para que possa ser utilizado na análise linguística. Entretanto, é importante esclarecer que o corpus em si é artificial, visto que se trata de textos organizados e selecionados, criando um objeto para fins de pesquisa, que podem se apresentar nas modalidades escrita, falada ou intermediária, podendo ser, essas amostras, de qualquer tamanho.

\section{Quadro 5 - Critérios para a Construção do Corpus da Pesquisa}

\begin{tabular}{|c|l|}
\hline Relevância & $\begin{array}{l}\text { Podem apresentar-se de forma escrita, falada ou intermediária, podendo ser } \\
\text { amostras de qualquer tamanho. }\end{array}$ \\
\hline Homogeneidade & Padrão de um mesmo tipo de material. \\
\hline Sincronicidade & Intersecção histórica dos materiais. \\
\hline
\end{tabular}

Fonte: adaptado de Van Dijk (2008).

Neste exemplo, é possível notar semelhanças e diferenças na abordagem de uma mesma história, neste caso, a morte da vereadora Marielle Franco, ocorrida em março de 2018, apesar da história ser a mesma, os jornais The New York Times e o britânico The Guardian apresentam narrativas totalmente distintas. Já o norte americano The Washington Post, traz nuvens de palavras extremamente semelhantes, mesmo em dias diferentes, explicitando fortes indícios de um possível racismo narrativo. Estas nuvens dão suporte ao analista, que analisará também as imagens da reportagem, a narrativa completa, o enquadramento da manchete e todo o contexto discursivo. 
Quadro 6 - Análise comparativa das nuvens de palavras de um corpus da pesquisa

\begin{tabular}{|c|c|}
\hline 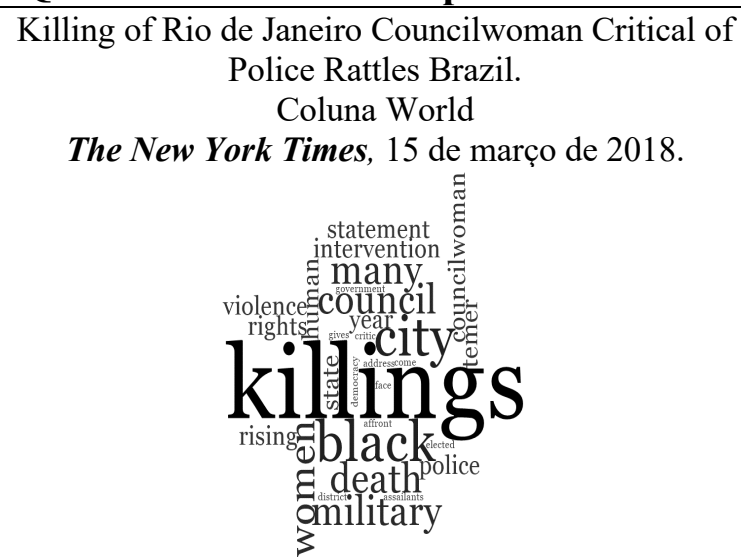 & $\begin{array}{l}\text { Marielle Franco: Brazil's favelas mourn the death } \\
\text { of a Champion. } \\
\text { Coluna World } \\
\text { The Guardian, } 18 \text { de março de } 2018 . \\
\text { brazilian }\end{array}$ \\
\hline $\begin{array}{l}\text { A black female politician was gunned down in Rio. } \\
\text { Now she's a global symbol. } \\
\text { Coluna World } \\
\text { The Washington Post, } 19 \text { de março de } 2018 . \\
\text { including }\end{array}$ & 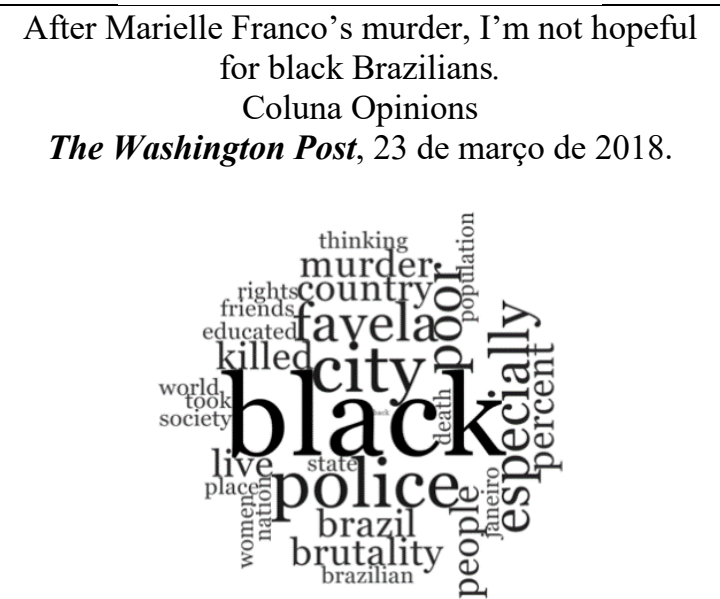 \\
\hline
\end{tabular}

Fonte: Adaptado de Danin (2018) com suporte do software NVIVO12.

A seguir um exemplo de um corpus utilizado em uma análise crítica do discurso. É importante ressaltar que, neste caso específico do exemplo, utilizamos um mesmo jornal para análise, mas o corpus pode e deve ser múltiplo, respeitando obviamente o critério para construção do corpus da pesquisa. 


\section{Quadro 7 - Versão online para o Reino Unido do jornal britânico The Guardian}

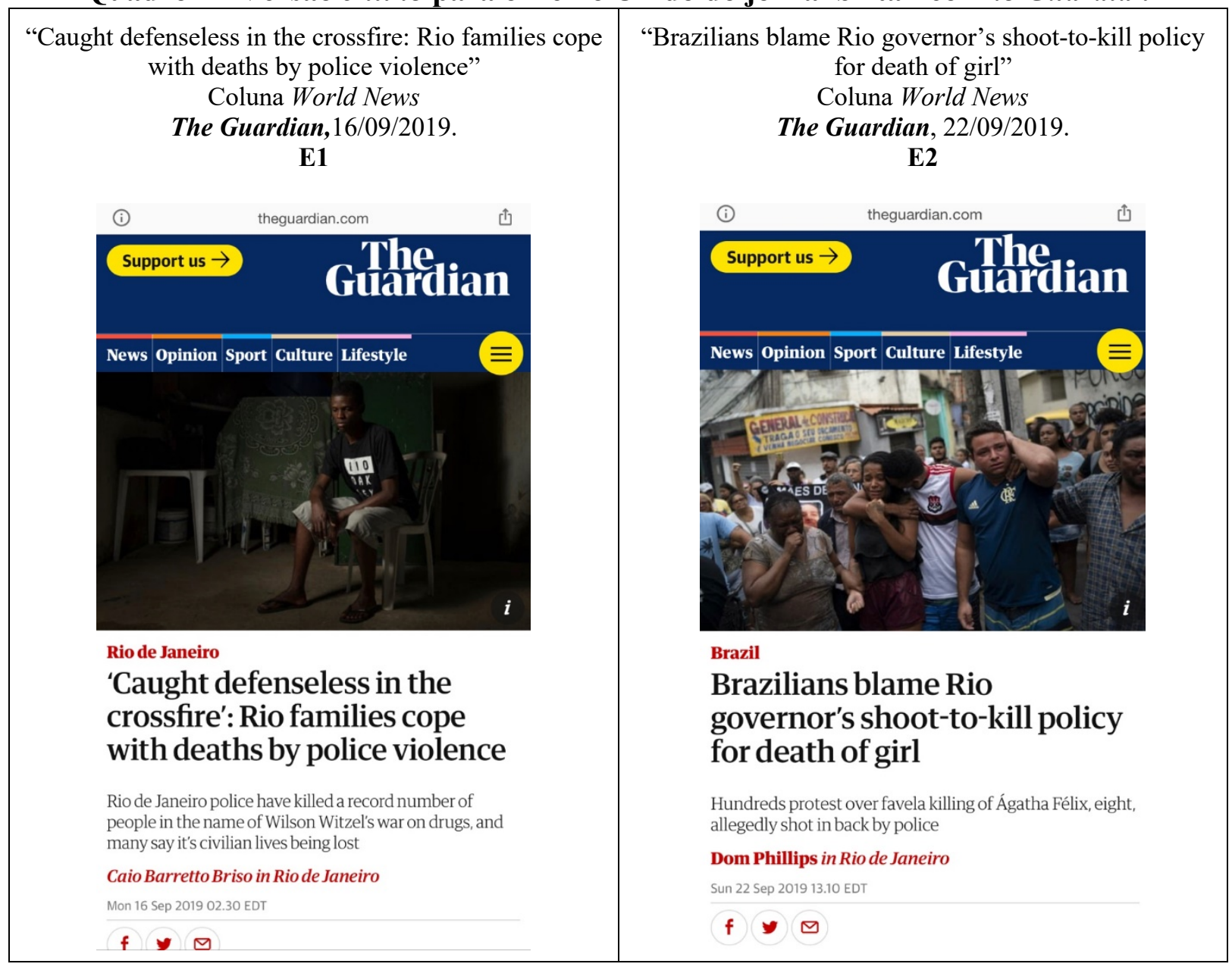

Fonte: Adaptado de Danin (2020).

A multiplicidade torna a pesquisa mais rica e facilita a percepção de padrões narrativos, porém esses padrões também podem ser identificados em um mesmo jornal, como exposto logo abaixo. Também ressalto que uma característica marcante em nossa pesquisa será a multiplicidade, de jornais, de narrativas, de histórias, mas sempre com o foco principal no racismo discursivo e o sujeito negro como ator principal dessas narrativas. Nosso intuito é chamar a atenção e ampliar a visão do leitor e do próprio jornalista ou formador de opinião para além dos modelos mentais atualmente constituídos, visando a construção de bases para um modelo de confecção e propagação de notícias menos enviesadas (do ponto de vista racial).

A análise das imagens também será utilizada para corroborar com a análise do discurso crítica para fins deste trabalho de pesquisa, pois acredita-se que enquadramento, iluminação, uso das cores, disposição dos atores, cenário, poses e demais expressões em uma capa de um jornal ou ao longo da própria reportagem, também ajudam a contar uma história, formar uma opinião, além de não serem escolhidas de forma aleatória, todas possuem um impacto e são escolhidas de acordo com algum critério, seja ele técnico ou mesmo subjetivo. No exemplo 
abaixo, temos duas imagens de capa da coluna World News do jornal britânico The Guardian, as fotos representam respectivamente o Rio de Janeiro e o Brasil em cada uma de suas reportagens. É possível observar a expressão facial dos personagens em cada foto, a pose, o comportamento da luz e diversas semelhanças narrativas, estas semelhanças podem ser identificadas nas imagens e ajudam a partir da cognição na formação de uma ideia sobre o que está sendo discursivamente oferecido.

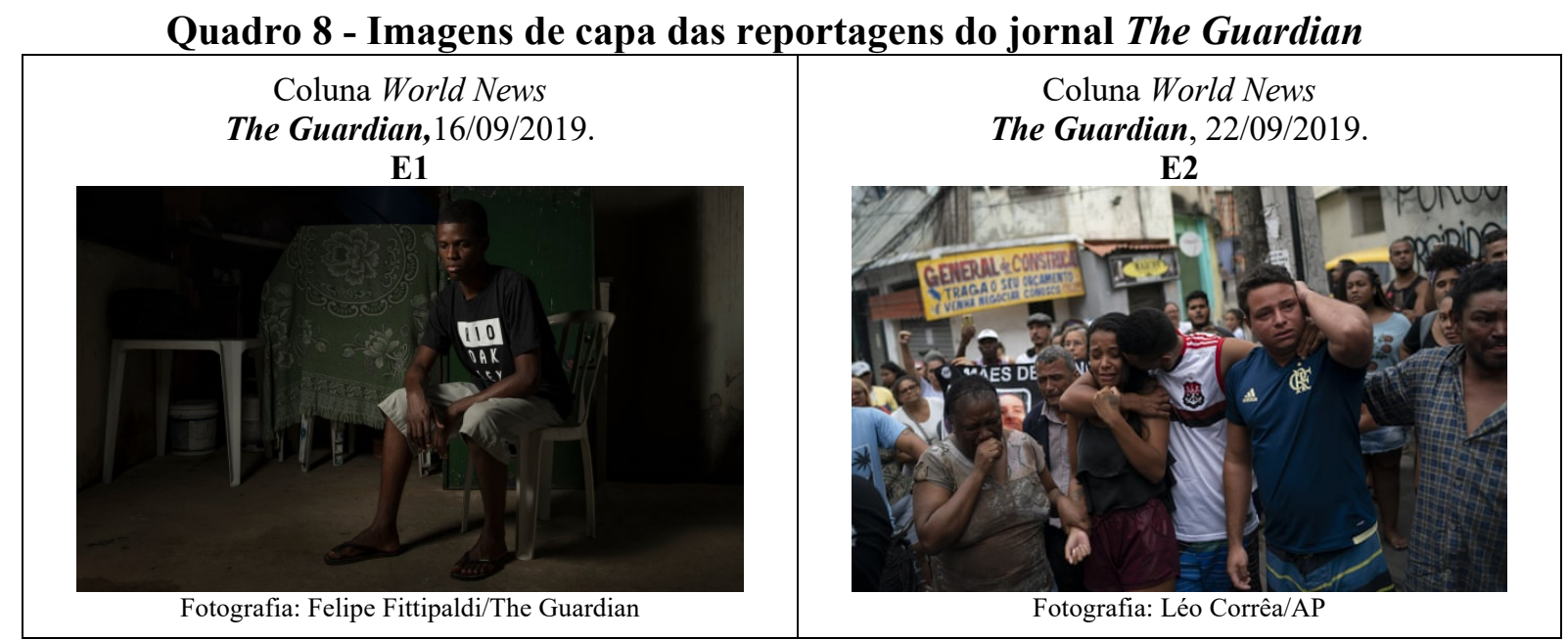

Fonte: adaptado de Danin (2020).

\section{Considerações Finais}

A grande contribuição da Análise Crítica do Discurso para os dias de hoje é demonstrar as camadas narrativas que se encontram além das palavras. Esta abordagem apresenta a cognição como ponto fundamental e revela pontos implícitos nos discursos que impactam a forma como as pessoas observam o sujeito negro na sociedade.

A ideia é compreender que existe uma estrutura social que é dona dos meios de comunicação (detém o discurso) e veicula narrativas com indícios de racismo a partir das notícias, e embora estas nuances não sejam perceptíveis de um ponto consciente, ainda assim trazem impacto na cognição de quem as lê, e é no subconsciente, num ponto subliminar e íntimo que se constrói uma ideia ou percepção que pode ajudar a construir e perpetuar uma imagem negativa do sujeito negro.

O racismo narrativo é sobre o que não se vê de forma explícita, mas que impacta de forma implícita e por isso traz um grau de nocividade social, sendo responsável pela 
manutenção das estruturas de poder e na dificuldade da construção de uma sociedade que repense o racismo estrutural.

Para fins de teste de método, foi possível observar indícios mais claros de um possível racismo narrativo em jornais estadunidenses e ingleses, como demonstrados em nossos exemplos, talvez o motivo principal a seja regra do one drop rule, que define claramente quem é branco e quem é preto nestes países.

Nosso desafio para os próximos trabalhos é encontrar nuances de racismo narrativo em jornais brasileiros e detectar suas particularidades e principais características, sempre com a finalidade de fomentar o debate em torno do racismo cotidiano afim de problematizá-lo, identificá-lo para, enfim, combatê-lo.

\section{Referências}

BOURDIEU, P. Esboço de autoanálise. São Paulo: Companhia das Letras, 2005.

CASTELLS, M. O poder da identidade - A era da informação: Economia, sociedade e cultura. São Paulo: Paz e Terra, vol. 2.2000.

A Galáxia da Internet - Reflexões sobre a internet, os negócios e a sociedade. Rio de Janeiro: Jorge Zahar, 2003.

CERQUEIRA, D. R. C.; MOURA, L. R. Vidas perdidas e racismo no Brasil. 2014. Disponível em: http://www.revistas2.uepg.br/index.php/sociais/article/view/6320/4137 Acesso em: 22 abr. 2017.

COLLINS, P. H. Black Feminist Thought. Knowledge, Consciousness, and the Politics of Empowerment. New York: Routledge, 2000.

CRI. Articulação para o Combate ao Racismo Institucional. Identificação e abordagem do racismo institucional. Brasília: CRI, 2006.

DA MATTA, R. Relativizando: uma introdução à Antropologia. Petrópolis: Vozes, 1984.

DANIN, R. A.; CARVALHO JÚNIOR, J. G.; REIS, T. R. Racismo discursivo: O caso Marielle Franco e a cobertura da mídia internacional. methaodos.revista de ciencias sociales, v. 6, n. 2, 15 oct. 2018. Acesso em: 22 nov. 2020. https://doi.org/10.17502/m.rcs.v6i2.243

DANIN, R.A. TEUN VAN DIJK: A CONSTRUÇÃO DA IMAGEM DO NEGRO LATINOAMERICANO POR UM JORNAL INTERNACIONAL. Policromias - Revista de Estudos do Discurso, Imagem e Som, 5(1), 131-155. 2020. Acesso em: 22 nov. 2020. https://revistas.ufrj.br/index.php/policromias/article/view/31217

FANON, Frantz. Black Skin, White Masks. London: Grove Press, 1967. 
FOUCAULT, M. Microfísica do poder. Organização e tradução de Roberto Machado. Rio de Janeiro: Edições Graal, 1979.

GIL, A. C. Método e técnicas de pesquisa social. $6^{a}$ ed., São Paulo: Atlas S.A, 2008.

GILROY, P. "There Ain't No Black in the Union Jack": The cultural Politics of race and nation. London: SAGE, 2001.

GONZALEZ, L. A categoria político-cultural de Amefricanidade. In Tempo Brasileiro, Rio de Janeiro, n. 92/93, p. 69-82, jan./jun. 1988

KILOMBA, G. Memórias da Plantação: episódios de racismo cotidiano. Tradução de Jess Oliveira. Rio de Janeiro: Editora Cobogó, 2019.

TELLES, E. Pigmentocracies: ethnicity, race, and color in Latin America. Chapel Hill: University of North Carolina Press. 2014.

VAN DIJK, T. A. Racism and the press. London: Routledge, 1991.

. New(s) racism: a discourse analytical approach. In: COTTLE, S. Ethnic minorities

and the media: changing cultural boundaries. Philadelphia: Open University Press, p. 33-49, 2000.

Discurso e poder. São Paulo: Contexto, 2008.

. Discourse and context. A socio-cognitive approach. Cambridge; New York: Cambridge University Press, 2008.

. Análise Crítica do Discurso. In: TOMAZI, Mattedi Tomazi. et al. Estudos discursivos em diferentes perspectivas: mídia, sociedade e direito. São Paulo: Terracota Editora, 2016, p. $19-35$.

WAiselfisZ, J. Mapa da Violência 2016: Mortes Matadas por Armas de Fogo, Rio de Janeiro, FLACSO/CEBELA, 2016.

WIEVIORKA, M. O Racismo, uma introdução. São Paulo: Perspectiva, 2007.

Data de recebimento: 29.10 .2020

Data de aprovação: 02.03.2021 